EESTI NSV TEADUSTE AKADEEMIA TOIMETISED, 26. KOIDE KEEMIA * GEOLOOGIA, 1977, Nr. 2

ИЗВЕСТИЯ АКАДЕМИИ НАУК ЭСТОНСКОИ ССР. ТОМ 26 ХИМИЯ * ГЕОЛОГИЯ, 1977, № 2

\title{
РАННЕДЕВОНСКАЯ ИХТИОФАУНА НА НОВОЙ ЗЕМЛЕ
}

Настоящее сообщение основывается на изучении коллекции бесчелюстных и рыб, собранной в 1973 г. В. И. Бондаревым (СЕВМОРГЕО) на Северном острове Новой Земли из основания девонского разреза, обнажающегося на п-ве Шмидта, расположенном к востоку от залива Русская Гавань. Разрез сложен пестроцветными песчаниками, алевролитами и доломитами общей мощностью $200 \mathrm{M}$. Остатки позвоночных обнаружены в двух местах: на северном склоне гор Веселых в центре полуострова (в темных красновато-бурых алевролитах) и на его восточном побережье возле ледника Чаева (в серых алевролитах). Остатки бесчелюстных и рыб, представленные обломками панцирей, плавниковых шипов, чешуй, реже цельных пластинок, часто образуют костную брекчию. Вместе с позвоночными найдены мелкие лингулиды.

Ихтиокомплекс, открытый на Новой Земле, явно раннедевонского возраста. Он содержит птераспиды - несколько мелких форм и одну крупную (последняя близка к Gigantaspis), неопределимый гетерострак с бугорками типа Tesseraspis; Cephalaspis с длинными рогами; представителя (нового?) рода арктолепид, две-три формы (новых?) акантодов и Porolepis ?. Такой состав свидетельствует о сходстве изученной фауны с фауной серии (группы), Вуд Бей нижнего девона Шпицбергена, которая трактовалась до сих пор как эндемичная.

В приводимом ниже обзоре птераспиды рассматриваются Л. Новицкой, остальные формы - Э. Марк-Курик.

Авторы искренне признательны В. И. Бондареву и его сотрудникам, любезно предоставившим собранную ими коллекцию для изучения.

Heterostraci: Pteraspididae indet. Мелкие формы представлены тремя целыми пластинками панциря и шестью их фрагментами. Из целых две пластинки широкие, яйцевидной формы (рис. $1, a, б)$. Их передний край выпуклый, задний - спрямленный, бока - пологозакругленные. Длина 2,9 cм, максимальная ширина 2 cм, отношение ширины к длине $69 \%$. Обе пластинки слабовогнутые, обращены вверх внутренней стороной. На одной из них сквозь разрушенный сетчатый слой панциря виден рисунок дентиновых гребешков. Последние расположены концентрически вокруг центра роста, немного смещенного от середины длины пластинки к ее заднему краю. Гребешки сравнительно широкие $(2,5-3$ на 1 мм), расположены параллельно переднему и боковым краям пластинки, их боковая зазубренность или отсутствует или выражена очень слабо. Одна из этих пластинок, очевидно, вентральная (рис. 1,б; рис. 2,a). На ней сохранились следы латеральных сенсорных каналов. Фрагменты пластинок (рис, 1, в; рис. 2,б) по форме сходны с 
вышеописанными, а по размеру немного крупнее. Их дентиновые гребешки несколько тоньше $(4-5$ на 1 мм) и также лишены зазубренности. Ввиду отсутствия надежных признаков вопрос о принадлежности фрагментов к этому таксону остается открытым. Третья из целых пластинок - узкая (рис. 1, 2). При сходных размерах она имеет заметно друғие пропорции. Ее длина 3,2 см, максимальная ширина (в передней части) 1,8 cм, отношение ширины к длине $56 \%$. Форма пластинки умеренно удлиненная. Ее передний край закруглен, очертания боков не ясны, задний край частично разрушен; создается впечатление, что он имел небольшой округлый срединный выступ. Гребешки (4-5 на 1 мм) расположены параллельно переднему и боковым краям пластинки. Положение центра роста не просматривается.

Крупная форма. В коллекции имеется один фрагмент центральной пластинки крупной птераспиды (рис. 1, 2). Пластинка видна изнутри. Ее передний край разрушен, задний слабовыпуклый и спрямленный, боковые края (сохранился правый) пологовыпуклые, в задней трети они образуют очень неглубокую выемку. Отпечаток скульптуры хорошо различим на небольшом участке у переднего края. Судя по нему, эта птераспида обладает тонкими гребешками (6,5 на 1 мм), имеющими гладкую поверхность и незазубренные края.

Материал по птераспидам Новой Земли, хотя и проблематичен в смысле систематики, интересен в сравнительном аспекте. Мелкие формы обнаруживают сходство со шпицбергенскими аберрантными птераспидами из серии Вуд Бей, описанными Н. Гейнц (Heintz, 1960) как Pteraspis? lyktensis и Pteraspis ? minor и выделенными Д. В. Обручевым (1964) в качестве рода Grumantaspis Obruchev. Новоземельские и шпищбергенские формы объединяет сходство орнаментов (широкие для таких размеров панциря гребешки с незазубренными краями) и очень небольшие размеры панциря, хотя первые почти вдвое крупнее вторых. Сходными формами обладают описанная выше небольшая узкая пластинка из новоземельской коллекции (рис. 1, 2) и дорсальная пластинка Pt.? minor. Однако их отличают размеры, значительно более крупные у новоземельской формы (согласно Н. Гейнц, у Pt.? minor длина дорсального диска $1,8 \mathrm{~cm})$, и положение центра роста. Последний занимает у обоих шпицбергенских видов гораздо более заднее положение, чем у новоземельских форм. Эти два отличительных признака - размеры и положение центра роста - свидетельствуют о том, что новоземельские птераспиды принадлежат, по-видимому, не к Grumantaspis, а к другому роду, выделение которого под новым названием нам представляется пока преждевременным из-за недостатка материала.

Фрагмент крупной птераспиды с Новой Земли размерами и орнаментом (тонкие незазубренные гребешки) очень напоминает описанного Н. Гейнц (Heintz, 1962) Gigantaspis также из серии Вуд Бей Шпицбергена. Возможно, новоземельская форма в будущем сможет быть отнесена к этому роду.

Heterostraci indet. Отдельные мелкие (порядка $1-2$ мм) бугорки несложной формы с простыми короткими зубчиками встречены в обоих местонахождениях п-ова Шмидта. Верхушки у них гладкие, ребрышки на боках отсутствуют. Некоторые бугорки (рис. $3, a, \sigma)$ удлиненные и плоскне (самый крупный имеет при длине 2,5 мм высоту 0,5 мм), другие короче и более выпуклые (рис. $4, a-8)$. Как показало изучение микроструктуры, бугорки пронизаны довольно грубыми дентиновыми канальцами, в их основании обнаружена губчатая ткань с полостями шарпеевых волокон. Бугорки принадлежат гетеростраку, определить который до рода или даже семейства пока невозможно. По внешнему 

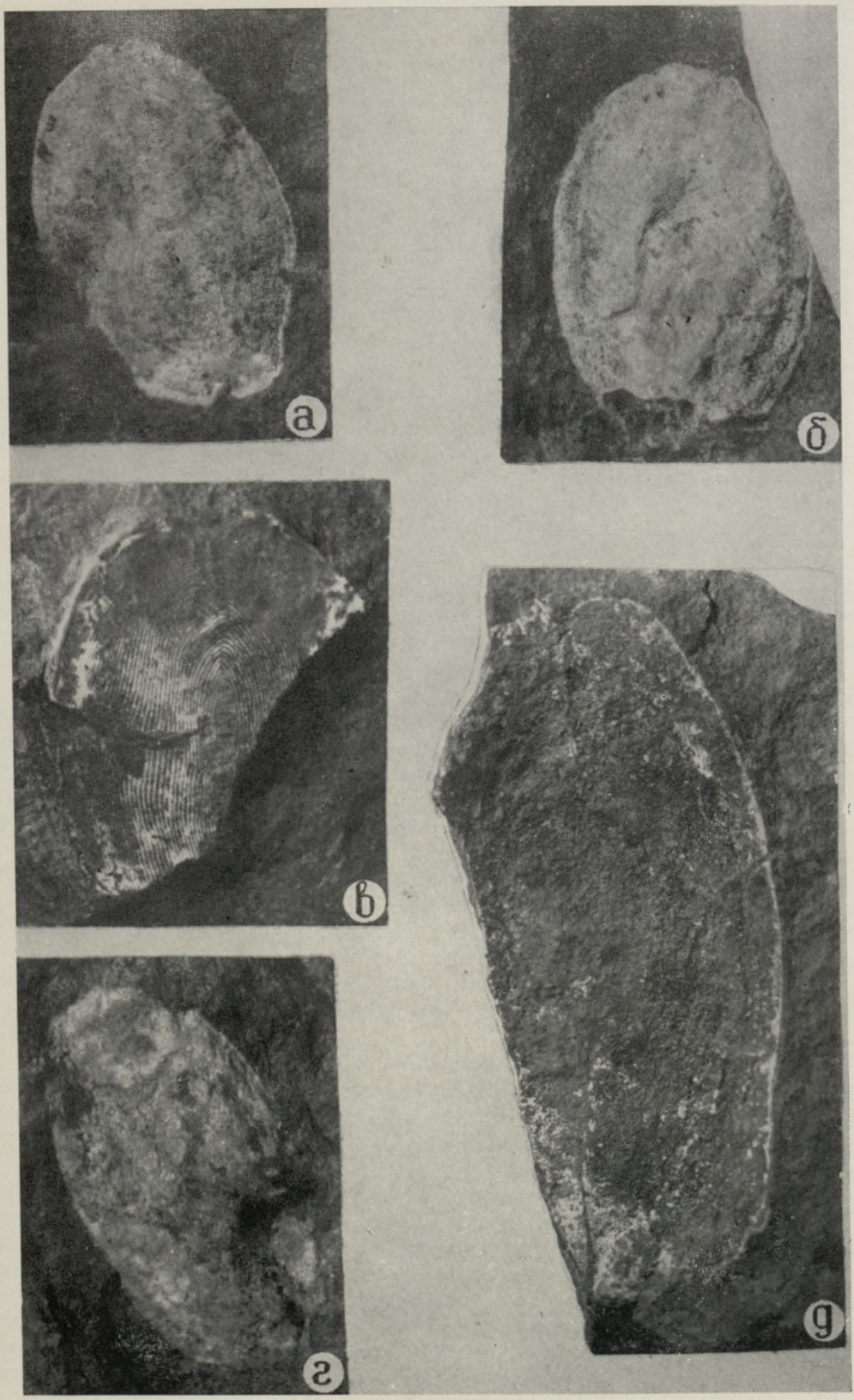

Рис. 1. Pteraspididae indet. Мелкие формы: $a, 6-$ широкие пластинки яйцевидной формы ( 6 - вентральная), в - фрагмент дорсальной пластинки, $z-$ узкая удли. ненная пластинка, $\times 2 ; \partial-$ крупная форма (фрагмент центральной пластинки), $\times 1$. 



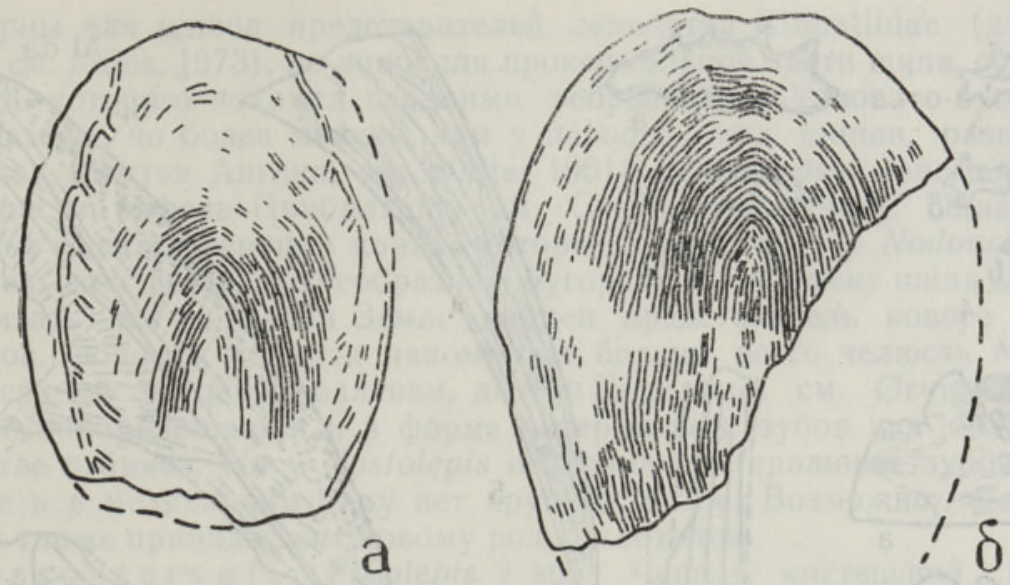

Рис. 2. Pteraspididae indet. Мелкие формы, $\times 2$ : $a-$ вентральная, $\sigma$ - дорсальная пластинки.

виду они напоминают бугорки орнамента цефаласпид. Но отсутствие полостей костных клеток не позволяет отнести их к представителям Osteostraci. Қак по форме, так и по микроструктуре эти бугорки ближе всего к кожным зубам Tesseraspis (диттон Англии, Литвы, Подолии).

Osteostrac i : Cephalaspis sp. in d et. Остатки цефаласпид представлены несколькими рогами (cornua), орнамент которых не сохранился. Система васкулярных каналов обнажена (рис. 5). Рога узкие, слегка изогнуты, направлены или назад или немного в сторону, зазубренности нет. Их длина 5,5-6 cм. Судя по размерам, эти остатки принадлежат какой-то форме Cephalaspis средней величины.

Новоземельский Cephalaspis напоминает, пожалуй, больше виды этого рода из серии Ред Бей, чем из серии Вуд Бей Шпицбергена. Первые имеют и короткие и длинные, но не слишком широкие рога, вторым же, наоборот, присущи сильно развитые и широкие (Wängsjö, 1952), хотя из нижней части серии Вуд Бей известны некоторые формы с довольно узкими и длинными рогами, например Cephalaspis jarviki Wängsjö (свита Кап Кьелдсен). Определение остатков Cephalaspis до вида мы считаем пока преждевременным.

Arthrodira: Arctole pidida n. gen.? У ледника Чаева найдена левая боковая часть брюшного панциря длиной 3 cм небольшой арктолепиды (рис. 6). Спинальная пластинка (Sp) сохранилась почти полностью, а соседние - межбоковая (IL) и вентрально-боковая (AVL) - лишь в виде фрагментов. Орнамент состоит из косых извилистых рядов, образованных овальными бугорками, размер которых резко уменьшается от латерального края в сторону передней боковой пластинки (от 0,6 до 0,2 мм). Свободный конец спинальной пластинки средней длины. На ее медиальном краю зазубренность отсутствует.

Форму с Новой Земли можно считать типичным представителем семейства Actinolepididae, если судить по спинальной пластинке, напоминающей одноименную пластинку Lataspis (Plataspis) $=$ «Actinolepis» (серия Вуд Бей Шпицбергена). Однако Lataspis по размеру крупнее и по орнаменту грубее. По этим двум признакам - скульптуре и величине - новоземельская арктолепида ближе к Ailuracantha dorsifelis White (брекон Англии, см. White, 1969). Но в принадлежности ее к этому роду заставляют усомниться отсутствие зазубренности на спинальной 


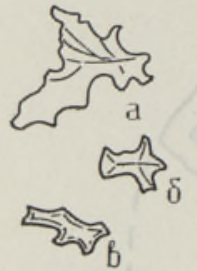

4
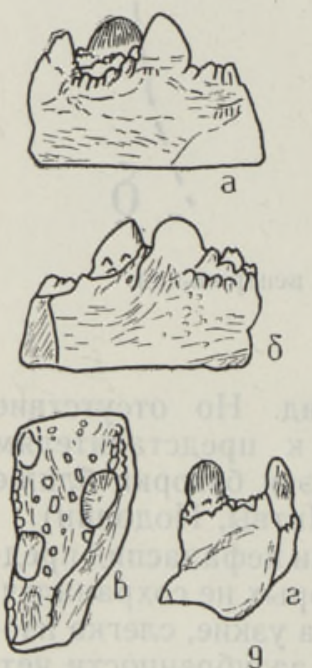
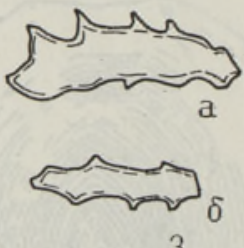

3

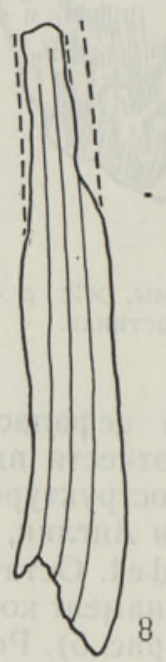

8

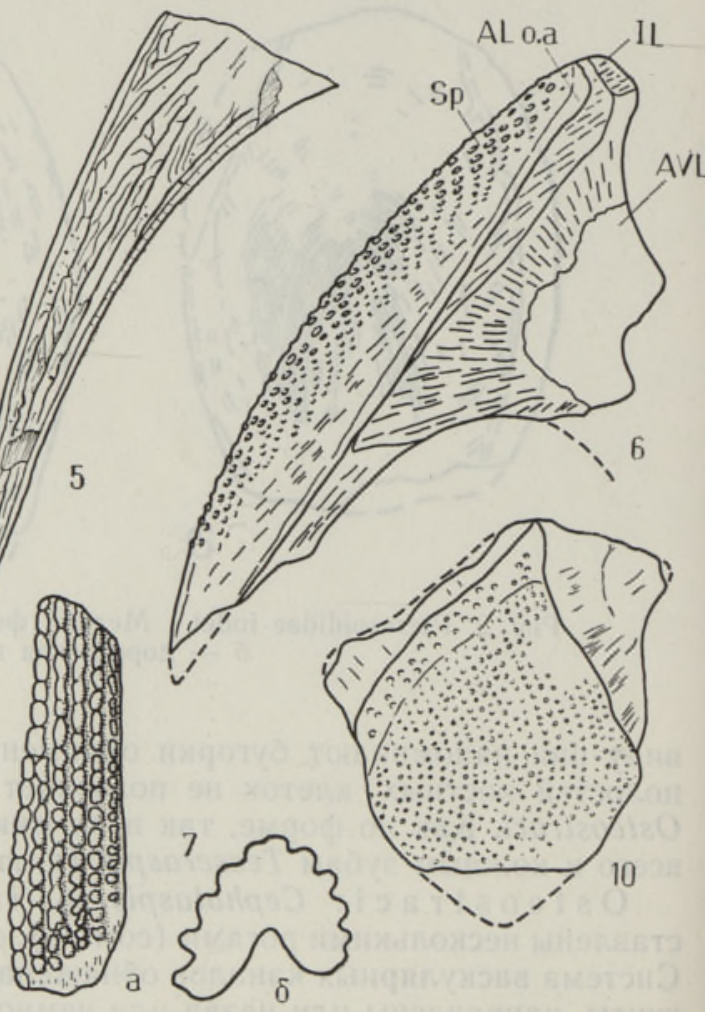

Рис. 3, 4. Heterostraci indet., бугорки типа Tesseraspis, $\times 10: 3, a, 6$ - удлиненные, $4, a-8-$ короткие. Рис. 5. Cephalaspis sp. indet, por (cornu), $\times 1$. Рис. 6. Arctolepidida п. gen. ?, левая боковая часть брюшного панциря, $\times 2,5: \mathrm{AL}$ o. a. - шовная поверхность передней боковой пластинки, AVL - передняя вентрально-боковая, IL - межбоковая, $\mathrm{Sp}-$ спинальная пластинки. Рис. 7,8 . Acanthodei, плавниковые шипы, $\times 2,5: 7, a-$ шип с бугорчатым орнаментом, 6 - он же в разрезе, рис. 8 - шип с гладкими ребрышками. Рис. 9. Acanthodei, фрагмент нижней челюсти, $\times 5$ : вид с латеральной $(a)$, медиальной (б) и дорсальной (в) сторон, вид сбоку (с). Рис. 10. Porolepis?, чешуя, $\times 5$.

пластинке, ее бо́льшая массивность и, видимо, шире расставленные свободные концы спинальных пластинок. Возможно, она будет отнесена к новому роду.

Ac anthodei. Остатки этих рыб представлены в коллекции плавниковыми шипами двух типов и обломком челюсти. Первый тип (рис. $7, a, 6)$ - обломок длиной $1,6 \mathrm{~cm}$ массивного, почти прямого шипа. Орнамент состоит из удлиненных бугорков, которые, сливаясь между собой, образуют ребрышки. На одной стороне шипа прослеживается до пяти шести ребрышек. Верхний канал над пульпарным не развит. В торой т и п - обломок длиной 2,4 см (рис. 8 ) - отличается от первого отсутствием бугорков. Он имеет четыре гладких плоских ребрышка. Чел юсть представлена довольно массивным обломком длиной 5,5 мм (рис. 9, $a-2$ ) с двумя крупными зубами - треугольным латеральным и куполовидным медиальным. Основание латерального зуба примерно овальное. Между этими зубами и вокруг них расположены неправильными рядами остроконечные одонтоды или зубики.

Судя по скульптуре, шипы принадлежат разным акантодам. Особенно интересен шип с бугорчатым орнаментом, так как шипы с гладкими ребрышками довольно типичны для акантодов. Бугорчатые ребрышки 
характерны для шипов представителей семейства Climatiidae (диттон Англии, см. Miles, 1973), но лишь для проксимальной части шипа, остальная часть которого покрыта гладкими ребрышками. Узловато-бугорчатый орнамент, но более мелкий, чем у первого типа шипов, развит у Nodonchus (диттон Англии, см. White, 1961) и Nodocosta (зиген Рейнской области, эйфель Прибалтики; см. Gross, 1933, 1940). Однако у Nodocosta имеется верхний кканал, который отсутствует у Nodonchus и новоземельской формы. Своеобразный бугорчатый орнамент шипа позволяет считать, что на Новой Земле найден представитель нового рода акантодов. Обломок челюсти напомннает больше всего челюсть Nostolepis (верхний силур Прибалтики, диттон Подолии?; cм. Ørvig, 1973). Сходство обнаруживается и в форме латеральных зубов и в большом количестве зубиков. Но у Nostolepis основание латеральных зубов треугольное и в медиальном ряду нет крупных зубов. Возможно, обломок челюсти также принадлежит новому роду акантодов.

Crossopterygi i: Porolepis? sp. Чешуи кистеперой рыбы (рис. 10) довольно крупные (высотой $7-10$ мм, толщиной до 3 мм), ромбические, с хорошо развитыми перекрываемыми поверхностями; покрытая космином поверхность пронизана мелкими круглыми порами (по 3-5 на 1 мм). На переднем краю свободной поверхности имеется полоска с небольшими бугорками, которые образуют до $3-5$ рядов. За полоской нет гребешков.

Полоской бугорков на свободной поверхности и отсутствием гребешков возле нее чешуи с Новой Земли напоминают чешуи Porolepis (жединзиген, курейская свита северо-запада Сибирской платформы и урюмские слои Таймыра; см. Воробьева, 1963). Но у последних поры реже и крупнее, а между свободной и перекрываемой поверхностями проходит борозда. Величина пор, толщина чешуй и ясно выраженный валик на висцеральной поверхности сближают чешуи с Новой Земли с чешуями Porolepis из серии Вуд Бей Шпицбергена. Однако у последних узкая полоска с орнаментом у свободной поверхности покрыта и бугорками и короткими гребешками (см. Jarvik, 1950; Ørvig, 1969). Из-за отсутствия гребешков на чешуях кистеперая, найденная на Новой Земле, отнесена к роду Porolepis несколько условно.

\section{Заключение}

Изучение раннедевонской ихтиофауны с п-ова Шмидта Новой Земли показало, что она ближе всего к одновозрастной ихтиофауне Шпицбергена. Об этом свидетельствуют в первую очередь птераспиды, которые близки к шпицбергенским птераспидам из серии Вуд Бей. Сходство имеют и представители цефаласпид и поролепид обоих регионов. Арктолепида и акантоды Новой Земли, возможно, эндемичные и представлены новыми родами. Гетеростраки с бугорчатым орнаментом, похожие на новоземельскую форму, из серии Вуд Бей не известны. Различия между вышеупомянутыми фаунами заключаются еще и в том, что в серии Вуд Бей найдены телодонты и очень богатый комплекс арктолепид, из которого ни одна форма не встречена на Новой Земле.

C точки зрения корреляции интересен вопрос - какой части серии Вуд Бей соответствует нижнедевонская толща с остатками рыб на Новой Земле? Серия Вуд Бей (зиген-эмс по международной шкале) разделяется на три свиты: Кап Кьелдсен, Ликта (Келтифьеллет) и Стьердален (Friend и др., 1966). Наиболее близкая к шпицбергенским формам крупная птераспида относится, возможно, к роду Gigantaspis, который является руководящим для свиты Кап Кьелдсен. Мелкие птераспиды по 
форме сходны с Pteraspis ? lyktensis и Pt.? minor из свит Ликта и Стьердален, но крупнее их. Новоземельский Cephalaspis похож на представителей этого рода из Ред Бей (сопоставляется с жедином) и из свиты Кап Кьелдсен серии Вуд Бей. Арктолепида с Новой Земли несколько напоминает Lataspis из свиты Ликта, но отличается от него меньшей величиной и орнаментом. Остатки акантодов, известные из серии Вуд Бей, в частности из свиты Кап Кьелдсен (см. Ørvig, 1967), не обнаруживают сходства в морфологии и величине с остатками, найденными на Новой Земле. Чешуи Porolepis? напоминают чешуи поролепида из свит Кап Кьелдсен и Ликта. Исходя из приведенных данных, можно полагать, что толща с раннедевонским ихтиокомплексом Новой Земли соответствует примерно нижнему подразделению серии Вуд Бей - свите Кап Кьелдсен Шпицбергена или нижней половине зигена. Представители же Acanthodei и нептераспидный гетерострак говорят скорее всего в пользу более древнего, чем более молодого возраста новоземельской раннедевонской толщи по сравнению со свитой Қап Кьелдсен.

Находки с Новой Земли имеют значение и с точки зрения палеобиогеографии. Они показывают, что раннедевонская ихтиофауна, встреченная в серии Вуд Бей Шпицбергена, не эндемичная, как считалось раньше, а имеет, хотя бы отчасти, более широкое распространение.

\section{ЛИ Т Е РА Т У Р А}

В ор обьев а Э. И. 1963. Род Porolepis из девона СССР. Палеонт. ж., № 2.

Об ру че в Д. В. 1964. Подкласс Heterostraci (Pteraspides). В кн.: Основы палеонтологии. Бесчелюстные, рыбы. М.

Friend P. F., Heintz N., Moody-Stuart M. 1966. New unit terms for the Devonian of Spitsbergen and a new stratigraphical scheme for the Wood Bay Formation. Arbok Norsk Polarinst. 1965. Oslo.

Gross W. 1933. Die Wirbeltiere des rheinischen Devons. Abh. Preuss. Geol. Landesanst. (N. F.), Nr. 154.

Gross W. 1940. Acanthodier und Placodermen aus Heterostius-Schichten Estlands and Lettlands. Publ. Geol. Inst. Univ. Tartu, Nr. 60.

Heintz N. 1960. The Downtonian and Devonian vertebrates of Spitsbergen. X. Two new species of the genus Pteraspis from the Wood Bay Series in Spitsbergen. Skr. Norsk Polarinst., No. 117.

Heintz N. 1962. Gigantaspis, a new genus of fam. Pteraspidae from Spitsbergen. A preliminary note. Arbok Norsk Polarinst. 1960. Oslo.

Jarvik E. 1950. Middle Devonian vertebrates from Canning Land and Wegeners Halvö (East Greenland). II. Crossopterygii. Medd. Gronland, 96, No. 4.

Miles R. S. 1973. Articulated acanthodian fishes from the Old Red Sandstone of England, with a review of the structure and evolution of the acanthodian shoulder-girdle. Bull. Br. Mus. Nat. Hist. (Geology), 24, No. 2.

Ørvig T. 1967. Some new acanthodian material from the Lower Devonian of Europe. J. Linn. Soc. (Zool.), 47, No. 311.

Ørvig T. 1969. Vertebrates from the Wood Bay Group and the position of the Emsian-Eifelian boundary in the Devonian of Westspitsbergen. Lethaia, 2, No. 4.

Orvig T, 1973. Acanthodian dentition and its bearing on the relationships of the group. Palaeontographica, A, 143.

White E. I. 1961. The Old Red Sandstone of Brown Clee Hill and the adjacent area. II. Palaeontology. Bull. Br. Mus. Nat. Hist. (Geology), 5, No. 7.

White E. I. 1969. The deepest vertebrate fossil and other arctolepid fishes. Biol. J. Linn. Soc., 1.

Wängs jö G. 1952. The Downtonian and Devonian vertebrates of Spitsbergen. IX. Morphologic and systematic studies of the Spitsbergen cephalaspids. Skr. Norsk Polarinst., No. 97.

Ннститут геологии

Академии наук Эстонской ССР

Палеонтологический институт

Академии наук СССР
Поступила в редакцию 29/XII 1975 


\section{Elga MARK-KURIK, L. NOVITSKAJA}

\section{VARADEVONI KALAFAUNA NOVAJA ZEMLJALT}

1973. a. leidis V. Bondarev Novaja Zemlja Põhjasaarelt Schmidti poolsaarelt alamdevoni kirjuvärvilisest kihikompleksist kalajäänuseid. Need kuuluvad tüüpilistele varadevoni kaladele, kes sarnanevad Teravmägedel kap kjeldseni kihistust leitud fossiilsete kaladega. Leiud tõendavad, et Teravmägede seni endeemiliseks peetud varadevoni kalafauna oli laiemalt levinud.

\section{Elga MARK-KURIK, L. NOVITSKAYA}

\section{THE EARLY DEVONIAN FISH FAUNA ON NOVAYA ZEMLYA}

In 1973 Early Devonian fish remains were found by V. Bondarev in the terrigenous rocks of the lower part of the Devonian section on the northern island of Novaya Zemlya Archipelago (Schmidt Peninsula, Russkaya Gavan region). The fossil fishes come from two localities. Their assemblage comprises heterostracans, i. e. pteraspids (large and small forms), and an indeterminate form with tubercles of the Tesseraspis type; indeterminate species of Cephalaspis; a new (?) arctolepid; acanthodians, belonging to new (?) forms, and Porolepis? sp.

The assemblage reveals a similarity to that of the Wood Bay Series of Spitsbergen. The large pteraspid is quite similar to Gigantaspis, the guide fossil of the Kap Kjeldsen Formation; the small forms resemble aberrant pteraspids from the Lykta and Stjordalen Formations, being, however, much larger than the latter; Cephalaspis sp. indet. is comparable to Cephalaspis species from the Red Bay Series and from the Kap Kjeldsen Formation of the Wood Bay Series; porolepid-scales resemble those from the Kap Kjeldsen and Lykta Formations.

The Early Devonian vertebrate-bearing strata on Novaya Zemlya may be roughly correlated with the Kap Kjeldsen Formation of Spitsbergen, indicating that the Early Devonian fish fauna of Spitsbergen, considered so far as an endemic one, was of a wider geographical distribution. 